\title{
O DESVIO DE FINALIDADE DO ESTÁGIO E O RECONHECIMENTO DO VÍNCULO EMPREGATÍCIO
}

\author{
Alessandra Correa Alves, Thaís Fernanda Nunes de Brito, Mari Angela Pelegrinni \\ Universidade do Oeste Paulista - UNOESTE. Curso de Direito, Presidente Prudente - SP. E-mail: \\ leleca1998@gmail.com
}

\section{RESUMO}

O presente artigo apresenta o estágio extracurricular como sendo uma atividade que possibilita ao estudante a prática daquilo que lhe fora apresentado em âmbito acadêmico. Os direitos e obrigações dos estagiários estão contidos na lei 11.788/2008. Aqui trataremos principalmente da hipótese em que o estágio é desvirtuado, deixando de proporcionar a vivência do aprendizado, sendo utilizado somente como mão de obra barata. $O$ artigo versa sobre a possibilidade de reconhecimento do vínculo empregatício, não havendo adequação nas atividades exercidas pelo estagiário com aquelas previstas no termo de compromisso, ou ainda, quando não condizem com a aplicação prática do âmbito acadêmico.

Palavras-chave: Direito. Estagiário. Trabalho. Desvirtuação. Relação de Emprego.

\section{THE DIVERSION OF PURPOSE OF THE INTERNSHIP AND THE RECOGNITION OF THE EMPLOYMENT RELATIONSHIP}

\begin{abstract}
The present article presents the extracurricular traineeship like being an activity that makes possible to a student the practice of what there had been introduced then in academic extent. The rights and obligations of the probationers are contained in the Law 11.788/2008. Here we will treat principally the hypothesis in which the traineeship is misrepresented, stopping providing the existence of the apprenticeship, being used only like cheap labor. The article is about the possibility of recognition of the contract of employment, when adaptation not is still in the activities practiced by the probationer with those predicted in the term of promise, or, when they do not match the practical application of the academic extent.
\end{abstract}

Key Words: Right. Internship. Work. Distortion. Employment Relationship. 


\section{INTRODUÇÃO E OBJETIVO}

É de conhecimento geral que a educação é a base de todo cidadão, entretanto, ter apenas o conhecimento teórico não se mostra suficiente para qualificar uma pessoa para o mercado de trabalho, é preciso também o desenvolvimento prático. Assim faz-se necessário a figura do estágio. $\mathrm{O}$ estágio oferece ao estudante uma oportunidade de adquirir experiência e segurança na carreira profissional escolhida, em um período de transição entre o ambiente escolar e o ambiente de trabalho.

A Lei n. 11.788, de 25.09.2008, denominada Lei do Estágio, procurou delimitar regras para o bom funcionamento do estágio, dentro das normas e com licitude condizente ao Estado de Direito.

O estágio é um instituto que em regra não gera vínculo empregatício, mas possui todos os requisitos pertinentes à relação de emprego. Em razão disso, há incidência de organizações que se utilizam do estágio como forma de obtenção de mão de obra de baixo custo, para desenvolver atividade fim que não possui quaisquer relações com o conteúdo acadêmico.

Portanto, essa abordagem se faz necessária, haja vista a necessidade de conceituar e apresentar as características distintivas do estágio, sua finalidade, bem como a possibilidade de reconhecimento do vínculo empregatício nos casos em que essas características específicas não forem respeitadas.

\section{METODOLOGIA}

O presente artigo desenvolveu-se a partir de levantamento de dados e informações em mídias virtuais, bem como livros, doutrinas, leis e jurisprudências pertinentes ao assunto.

\section{CONCEITO DE ESTÁGIO}

De acordo com o artigo 1으 da lei de estágio, o estágio pode ser conceituado como sendo um "ato educativo escolar supervisionado, desenvolvido no ambiente de trabalho, que visa à preparação para o trabalho produtivo de educandos que estejam frequentando o ensino regular em instituições de educação superior" (BRASIL, Lei no 11.788/2008, de 25 de setembro de 2008).

Segundo Buriolla (2011. Pág. 13) “o estágio é concebido como campo de treinamento".

Portanto, entende-se o estágio como sendo um propiciador de atividade pratica ao estudante, contribuindo com sua formação profissional.

Não se confunde com a figura do aprendiz. O aprendiz, segundo a definição do Ministério do Trabalho e Emprego, consiste em formação técnico-profissional metódica que permite ao 
jovem aprender uma profissão, e obter experiência como trabalhador (art. 428 da CLT). As atividades desenvolvidas não precisam se adequar ao conteúdo programático do curso e suas especificações são determinadas pela Consolidação das Leis do Trabalho.

\section{OBJETIVOS E CARACTERÍSTICAS DO ESTÁGIO}

O estágio pode ser obrigatório (definido como tal no transcorrer do curso com carga horária obrigatória como requisito para obtenção do diploma) ou não obrigatório (desenvolvido por livre escolha ou como atividade opcional).

O estágio não obrigatório (extracurricular), aqui em foco, é regulamentado pela lei 11.788/2008 e diz respeito aos direitos e deveres concernentes aos estagiários.

Deve ser celebrado com estudante com idade igual ou superior a 16 anos, mediante termo de compromisso devidamente assinado pelo estagiário, pela parte cedente e pela instituição de ensino, por período não superior a 2 (dois) anos (exceto em casos de estagiário portador de deficiência).

A jornada de trabalho do estágio consta nos incisos do art. 10 da supra lei e varia de acordo com o tipo de ensino desenvolvido pelo discente.

Fornece ao estudante domínio das atividades que lhe será exigida ao empenhar a futura profissão, e não somente o conhecimento teórico que the é transmitido em sala de aula. 0 estudante por sua vez, aplica na prática o que fora aprendido na Instituição de ensino, aproximando-se de sua profissão (PORTO, 2014).

Ao estagiário, na hipótese do estágio não obrigatório, será compulsória a concessão de bolsa auxílio (ou outra forma de contraprestação acordada) bem como auxílio-transporte, devendo ainda ser amparado pelo seguro contra acidentes no trabalho.

Haverá ainda, ao estagiário com contrato igual ou superior a um ano, direito de recesso de 30 dias remunerado, ou proporcional se inferior a um ano de vigência.

\section{DESVIRTUAÇÃO DO ESTÁGIO}

Como já fora mencionado anteriormente, para caracterização do contrato de estágio, são necessários alguns requisitos essenciais, um deles é a adequação do estágio ao teor acadêmico do estudante.

Em se tratando de estágio remunerado, há uma proximidade relevante com o instituto da relação de emprego, visto que reúne os requisitos caracterizadores desta - trabalho por pessoa 
física, com pessoalidade, não eventualidade, onerosidade e mediante subordinação (PAULA, 20022004).

Ora, uma vez que o que distingue o estágio da relação de emprego convencional é a aplicação da matéria aprendida em âmbito escolar. Ausente tal objetivo, desvirtua-se a finalidade do estágio, que é levar ao estudante o aprendizado prático que Ihe será exigido na futura profissão.

Desse modo não se pode descartar a hipótese em que o estágio é desvirtuado, a fim de substituir o empregado por estagiários, com objetivo de atender a mão-de-obra desqualificada, livrando-se dos direitos trabalhistas e previdenciários e redução dos custos de produção, ferindo os princípios constitucionais acerca da legislação trabalhista.

Por essa e outras razões, o estágio só deverá ser aceito quando houver efetiva formação e propiciando ao estagiário uma habilitação profissional específica ao seu ramo de estudo.

\section{RECONHECIMENTO DO VÍNCULO EMPREGATÍCIO}

O estágio, se observado os requisitos, não gera vínculo empregatício (art. 3으 da lei 11.788/2008), contudo, quando tais requisitos são descumpridos, há a possibilidade de reconhecimento do vínculo (§ 2ㅇart. 3o da lei 11.788/2008).

Entende-se por vínculo empregatício, ou relação de emprego, o fato jurídico que se configura quando uma pessoa física (pessoalidade) presta serviço à outra pessoa (física ou jurídica), com subordinação, de maneira não eventual e onerosa.

Com o reconhecimento do vínculo empregatício, o estagiário passa a ter os direitos regidos pela legislação trabalhista e previdenciária, uma vez que estará sobre a égide de uma relação de emprego.

O vínculo não poderá ser reconhecido em casos de desvirtuação ocorrida em administrações públicas, uma vez que a admissão é feita mediante concurso público. "Nestes casos serão devidos, apenas, o pagamento de saldo de salários e depósitos do FGTS (Fundo de Garantia por Tempo de Serviço), por força do disposto no Enunciado 363 do TST" (PORTO, 2014).

Para fins de esclarecimentos, relacionamos os seguintes acórdãos:

COMPROMISSO DE ESTÁGIO. DESVIRTUAMENTO. O estágio legalmente constituído possui finalidade social e educacional, pois possibilita que o aluno adquira experiência prática para futura colocação no mercado de trabalho, motivo pelo qual a lei veda o reconhecimento da relação de emprego. Todavia, se as atividades desempenhadas pelo estagiário junto à concedente não guardam relação com seu curso de formação, patente o desvirtuamento do estágio, motivo por que impõe-se o reconhecimento do vínculo empregatício 
entre as partes. (TRT-10 - RO: 1734201100710007 DF 01734-2011-007-10-007 RO, Relator: Desembargador Pedro Luis Vicentin Foltran. Data de Julgamento: 10/10/2012, 1a Turma, Data de Publicação: 19/10/2012 no DEJT).

ESTÁGIO x VÍNCULO DE EMPREGO. Fica obstado o reconhecimento da regularidade do contrato de estágio quando não foram observadas as disposições legais, especialmente as contidas no artigo 5으, do Decreto n.은 $87.497 / 82$, e $\S$ 3으, do art. 1으, da Lei $6.494 / 77$. Assim, forçoso declarar que o vínculo que uniu as partes, no período em debate, é de natureza empregatícia. Recurso improvido. (TRT-23 - RO: 578200500323002 MT 00578.2005.003.23.002, Relator: DESEMBARGADOR TARCÍSIO VALENTE. Data de Julgamento: 23/05/2006, Tribunal Pleno, Data de Publicação: 19/06/2006).

VÍNCULO DE EMPREGO. ESTÁGIO. Não comprovado o preenchimento dos requisitos essenciais do contrato de estágio, nos moldes da Lei no 6.494/77 e do Decreto $n$ o 87.497/82, impõe-se o reconhecimento da existência de relação de emprego entre as partes. (TRT-4 - RO: 00012762620125040029 RS 000127626.2012.5.04.0029, Relator: RICARDO HOFMEISTER DE ALMEIDA MARTINS COSTA, Data de Julgamento: 13/03/2014, 29a Vara do Trabalho de Porto Alegre).

Há ainda hipóteses em que contratam empregados com a máscara de estagiários, mas que sequer estão desenvolvendo atividades acadêmicas.

É o caso de uma estagiária de direito, já graduada, mas sem carteira da Ordem dos Advogados do Brasil.

Ela prestava serviços não eventuais, com subordinação, pessoalidade e onerosidade em escritório de advocacia, atendendo aos requisitos da relação de emprego, mas denominada estagiária, mesmo não se enquadrando nos requisitos dispostos no artigo 3o da Lei 11.788/2008.

É o que diz publicação em artigo da revista eletrônica Consultor Jurídico (2014):

Ao analisar o caso, o relator, juiz convocado Oswaldo Tadeu Barbosa Guedes, afastou a aplicação do artigo 3ㅇ da Lei Geral do Estágio (Lei 11.788/2008), que diz que o estágio não cria vínculo empregatício de qualquer natureza, pois a norma trata especificamente do caso de estudantes. "O caso dos autos não se trata de estágio de estudante, e sim de estágio de bacharel em Direito, já graduado, o que afasta a aplicação do aludido artigo, levando à inexorável conclusão de que o estágio do bacharel é prestado em caráter profissional, ocorrendo, portanto, o vínculo de emprego", afirmou.

Para reforçar o entendimento, o juiz citou parecer jurídico assinado pelo advogado Estevão Mallet, a pedido da OAB-SP: “O estágio profissional de advocacia, prestado, no caso, pelo bacharel, caracteriza, quando presentes os requisitos dos arts. 20 e 30 , da $\mathrm{CLT}$, relação de emprego, tendo em vista não incidir a excludente da Lei 11.788", afirmou o advogado no documento.

Portanto, nota-se que há o mau uso da lei de estágio até mesmo depois de concluídos os cursos de nível superior. 


\section{CONCLUSÃO}

Diante o assunto abordado, evidencia-se a importância de se respeitar o instituto do estágio, uma vez que visa preparar o estudante para a vida profissional. Reforça-se a ideia de que um profissional bem preparado proporciona uma sociedade com mais qualidade.

Uma eventual desvirtuação do estágio atinge todo ramo social, pois impossibilita uma atuação de qualidade, pertinente à profissão pretendida.

O papel de todo cidadão é o de não ser conivente com esta espécie de fraude trabalhista, recorrendo aos órgãos competentes a fim de fiscalizar e acabar com sua incidência. Cabe ainda à instituição de ensino supervisionar as condições em que o estágio ocorre.

Por fim, cabe ao estagiário buscar os seus direitos com o intuito de contribuir para que esta prática abusiva cesse.

\section{REFERÊNCIAS}

BRASIL. Congresso Nacional. Lei do estágio. Lei n. 11.788 de 25 de setembro de 2008. Dispõe sobre o estágio de estudantes; altera a redação do art. 428 da Consolidação das Leis do Trabalho CLT, aprovada pelo Decreto-Lei $n^{\circ} 5.452$, de $1^{\circ}$ e de maio de 1943 , e a Lei $n^{\circ}$ 9.394, de 20 de dezembro de 1996; revoga as Leis $\mathrm{n}^{\mathrm{os}} 6.494$, de 7 de dezembro de 1977, e 8.859, de 23 de março de 1994, o parágrafo único do art. 82 da Lei nํ⒐394, de 20 de dezembro de 1996, e o art. 6ํำ da Medida Provisória nํㅜㄴ.164-41, de 24 de agosto de 2001; e dá outras providências. Diário Oficial da União, Brasília, DF, 16 set. 2008. Disponível em:

<http://www.planalto.gov.br/ccivil_03/_ato2007-2010/2008/lei/l11788.htm>. Acesso em: 07 ago. 2014.

BRASIL. Consolidação das Leis do Trabalho. Decreto-Lei, n.ํ 5452, de 1 de maio de 1943. Das Normas Gerais de Tutela do Trabalho. Disponível em: <http://www.planalto.gov.br/ccivil_03/decreto-lei/del5452.htm>. Acesso em: 07 ago. 2014.

BURIOLLA, Marta A. F. O estágio supervisionado. Ed. 7. São Paulo: Cortez, 2011. Pág. 13

PAULA, Pedro Delgado de. Contrato de estágio como meio fraudulento de contrato de trabalho. Jus Navigandi, Teresina, ano 9, n. 200, 22 jan. 2004. Disponível em: <http://jus.com.br/artigos/4773>. Acesso em: 6 ago. 2014.

PORTO, Marcelo da Silva. O Contrato de Estágio Extracurricular: A fraude e sua desvirtuação. Disponível em: <http://www.ambito-

juridico.com.br/site/?n_link=revista_artigos_leitura\&artigo_id=11024\&revista_caderno=25.> Acesso em: 30 de mar. 2014.

ROVER, T. Relação de Emprego. Estagiária Profissional em direito tem vínculo empregatício reconhecido com escritório, ago., 2014. Disponível em: < http://www.conjur.com.br/2014-ago14/estagiaria-direito-vinculo-empregaticio-escritorio>. Acesso em: 14 ago. 2014. 